\title{
Fan Noise for a Concept Commercial Supersonic Transport
}

\author{
David B. Stephens* \\ NASA Glenn Research Center, Cleveland, Ohio, 44135.
}

\begin{abstract}
Supersonic commercial aircraft noise predictions have frequently considered only exhaust noise from the jet engines. Meeting the stringent noise requirements that apply to the subsonic fleet will require reducing jet exhaust noise to the point that fan noise may also require reduction. This report discusses the prediction of fan noise for a supersonic commercial aircraft using existing empirical noise models. Wind tunnel test data from three high pressure ratio fans were compared with the predictions. A two-stage fan was found to agree with predictions to with $1 \mathrm{~dB}$ EPNL in a simulated flyover. For a single stage fan, the prediction was found to be higher by nearly $6 \mathrm{~dB}$ EPNL. The two types of fans were then scaled to the same thrust and flyover noise was compared. The two-stage fan was found to be louder by $4 \mathrm{~dB}$, although effect on vehicle aerodynamics and sonic boom were not investigated in the present report.
\end{abstract}

\section{Introduction}

NASA is studying a conceptual commercial supersonic transport (CST) aircraft that could carry 35+ passengers at Mach 1.6+ with a $4000+\mathrm{nm}$ range. The aircraft design objectives also include environmental goals for sonic boom, airport noise and emissions at cruise. This vehicle is smaller and slower than much of the previous NASA CST work. For example, the NASA High Speed Research (HSR) project ran from 1990 to 1999 and focused on the vehicle called the High Speed Civil Transport (HSCT). The HSCT was a 300 passenger, Mach 2.4 aircraft with a $5000 \mathrm{~nm}$ range. Noise analyses for that vehicle ${ }^{1}$ and others ${ }^{2}$ only considered the jet exhaust noise component of the total aircraft noise. This is a fair assumption for the HCST, but the source component contributions may be different for a smaller vehicle with engines that reduce the take off jet noise with noise reduction devices or operational procedures.

A recent study using the current NASA CST goals resulted in the Lockheed Martin $1044 .{ }^{3}$ This aircraft would use three podded variable cycle engines. The study found that fan noise may be a meaningful contributor to overall vehicle noise at some acoustic rating conditions. The engines for this aircraft incorporate axillary inlet doors, multiple fan streams and other complications that may increase the radiated fan noise. Before these details can be accounted for, the noise due to the CST fan in a simple installation needs to be validated. Researchers at NASA have studied the noise impact on a fan downstream of a supersonic inlet and found that the axillary inlet doors increased fan noise substantially. ${ }^{4}$

This report describes investigations of empirical fan noise models, including comparisons of tone and broadband component levels, along with directivity. The NASA concept aircraft is similar in size and mission to the Lockheed Martin 1044, but the engine cycle and design is still open. Both single stage and two stage fans are being considered, so both are discussed in the current paper. This report concludes with recommendations for the use of fan models as part of the overall noise prediction process for this class of aircraft.

\section{Fan Noise Prediction}

NASA's principle aircraft noise prediction tool package is ANOPP2, the second generation of NASA's Aircraft Noise Prediction Program. ${ }^{5}$ Among the many noise tools it includes, this software package incorporates two empirical fan noise models, the Heidmann fan model ${ }^{6-9}$ and the HSRNOISE fan model. ${ }^{10}$ These

${ }^{*}$ Research Aerospace Engineer, Acoustics Branch, MS 54-3, 21000 Brookpark Road. AIAA Lifetime Member. 
models require a few basic engine geometric details along with operating conditions to estimate the tone and broadband components of the fan noise source. ANOPP2 also includes methods for noise source modifications, which might be used to account for the effect of inlet struts or bypass doors. Finally, ANOPP2 provides tools to propagate these noise sources to an observer on the ground, simulating an aircraft flyover, generating Perceived Noise Levels (PNL) traces and Effective Perceived Noise (EPNL) values. This section provides a brief background of the fan models.

\section{II.A. Heidmann Fan Model}

The Heidmann fan noise model was developed by Marcus Heidmann at NASA Lewis (now Glenn) Research Center based on data acquired from a full-scale outdoor fan rig. ${ }^{6}$ The method was later amended with additional capabilities for small fans by AlliedSignal Engines (now Honeywell Aerospace). ${ }^{7}$ GE Aircraft Engines (now GE Aviation) provided parameters to match three of their large fans fans. ${ }^{8}$ Finally, the NASA Source Diagnostic Test fan (designed by GE and also referred to as R4) was evaluated and modifications by Kresja and Stone were proposed. ${ }^{9}$ Thus there are four versions of the "Heidmann" fan noise model. The pressure ratio and tip speed of the fans used to develop the Heidmann fan model variations are shown in Figure 1. If a single-stage, high pressure ratio fan is selected for a commercial supersonic aircraft engine, only the very right-most side of the graph is relevant.

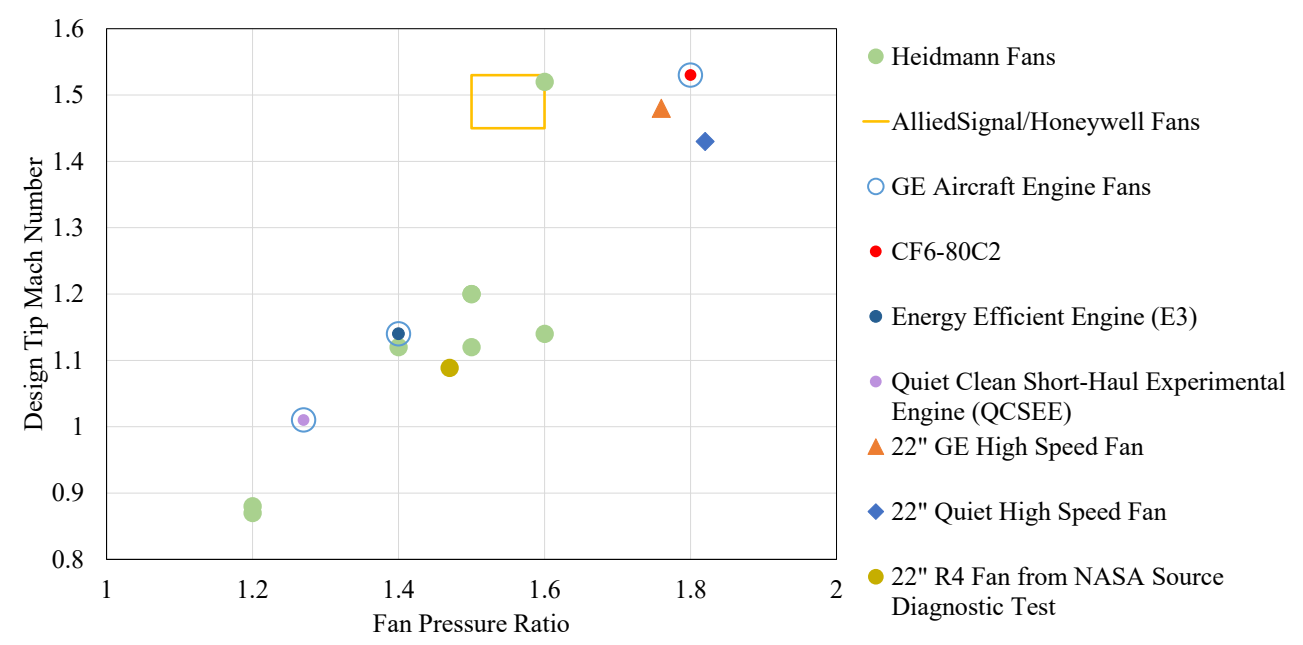

Figure 1: Fans used to develop the Heidmann model, along with fans considered in this report.

The Heidmann fan model includes following five noise components: 1) inlet radiated broadband, 2) inlet radiated blade passing tone and harmonics, 3) inlet radiated multiple pure tones, 4) aft radiated blade passing tone and harmonics and 5) aft radiated broadband. The first three are the focus of the present study, because it is assumed aft radiated fan noise would be sufficiently attenuated by the turbomachinery and nozzle sections of a CST engine.

The Heidmann method has been evaluated against modern low pressure ratio fans tested at the NASA GRC 9x15 LSWT, see section 5.7.1 of the report by Dahl. ${ }^{11}$ Much of the recent NASA fan noise work has focused on low pressure ratio fans with subsonic tip speed and a similar validation assessment has not been done for higher pressure ratio fans such as those needed for a supersonic aircraft.

\section{II.B. High Speed Research Fan Model}

As part of the HSR program, an aircraft system noise tool separate from ANOPP was developed. This program, known as HSRNOISE, ${ }^{10}$ was specifically focused on community noise from a commercial supersonic aircraft. The fan noise model included with this tool is an empirical fit to fan noise measurements from an experimental engine designed by GE, designated the XF-120. This engine used a multi-stage fan, although it is assumed only the first stage contributes to the noise. The model includes only inlet radiated noise, both tone and broadband and is found in Section 3.6 of the HSRNOISE report. This model is uses only inner and outer fan diameter, fan rotation rate and number of fan blades as input. 


\section{Validation}

These two fan models were developed based on experimental data using well-publicized methods. Their overall credibility is established. The present "validation" exercise considers how to best apply them as the NASA CST team works to optimize a vehicle and engine. The Lockheed-Martin 1044 design effort with $\mathrm{GE}^{3}$ used a two-stage counter-rotating fan with a tip fan, which is not like the engines used to develop the fan models. The NASA team has been considering both single-stage and two-stage (co-rotating) fans, so both were in the scope of the present effort. Measurements of fan noise from many scale models have been acquired in the 9- by 15-Foot Low Speed Wind Tunnel (9x15 LSWT), and several were considered to be good candidates for comparison with the fan noise models at high tip speed conditions. Specifically, three test campaigns were evaluated: The General Electric High Speed Fan ${ }^{12}$ (GE HSF), the Honeywell Quiet High Speed Fan $^{13}$ (QHSF), and a two-stage fan. A few key parameters of these fans are summarized in Table 1. These three fan programs span a useful range of the engine designs being considered for a current CST being considered. The single-scale fan models "QHSF" and "GE HSF" are included in Figure 1. The three fans will each be discussed in more detail in Sections V, VI and VII.

Table 1: Fans used for comparisons.

\begin{tabular}{|c|c|c|c|}
\hline & 2-Stage Fan & QHSF & GE HSF \\
\hline Scale & Model & Model & Model \\
\hline Blade Count & 26 & 22 & 24 or 34 \\
\hline Vane Count & 72 & 52 & 52 or 80 \\
\hline Inlet Annular Area, $m^{2}\left(f t^{2}\right)$ & $0.162(1.74)$ & $0.216(2.32)$ & $0.222(2.39)$ \\
\hline Fan rotor diameter, $\mathrm{cm}$ (in) & $48(19)$ & $56(22)$ & $56(22)$ \\
\hline Hub/Tip Ratio & 0.34 & 0.35 & 0.31 \\
\hline Design $R P M$ & 16670 & 15444 & 15105 \\
\hline Design Pressure Ratio & 2.4 & 1.82 & 1.76 \\
\hline Tip Speed, $\mathrm{m} / \mathrm{s}(\mathrm{ft} / \mathrm{s})$ & $429(1406)$ & $449(1474)$ & $442(1450)$ \\
\hline Axial Rotor-stator spacing (rotor chords) & 0.55 & 2.4 & 2.54 \\
\hline Corrected Fan Airflow, $\mathrm{kg} / \mathrm{s}(\mathrm{lbm} / \mathrm{s})$ & $29.9(66.0)$ & $44.9(98.9)$ & $45.4(100)$ \\
\hline Average Bypass Fan Temperature Ratio & 1.32 & 1.21 & 1.21 \\
\hline
\end{tabular}

\section{Fan Noise Source Separation}

To isolate the inlet and aft fan noise experimentally, a floor-to-ceiling barrier wall is used in the tunnel to block aft fan noise from reaching the sideline microphone. The barrier wall was in place for all the measurements used in this report.

With the inlet noise isolated experimentally, the tone and broadband portions of the measured spectra were separated with the use of a modified moving median filter, as described in Section 3 of Stephens \& Vold. ${ }^{14}$ The method identifies the "broadband" portion of the spectra, which is then subtracted from the total spectra to get the "tonal" portion of the spectra. Tone levels were calculated by summing the narrowband value at the frequency nearest the expected tone frequency, plus one on each side $( \pm 59 \mathrm{~Hz}$ for the data sets used here) to account for RPM variation or tone energy split between frequency bands. The moving median spectra was also summed across the same bins. The difference in the two values was taken to be the tone level. The tones occurring at the first six multiples of the blade passing frequency are kept as "BPF tones." Remaining tones below 2-times BPF are kept as "MPTs" if the tip Mach number is above 1. Other tone energy is not considered when comparing measured noise components with prediction models. Frequencies below $1000 \mathrm{~Hz}$ or above $41 \mathrm{kHz}$ are disregarded due to excess background noise the facility and the lack of confidence in high-frequency noise measurement, respectively. An example processing result is shown in Figure 2. This method allows the individual components of the noise model to be compared against the individual measured sound components. The narrowband spectra for the three components are converted to one-third octave band levels, to match the output from the fan models. 
RDG 2554, Angle $=62.9$
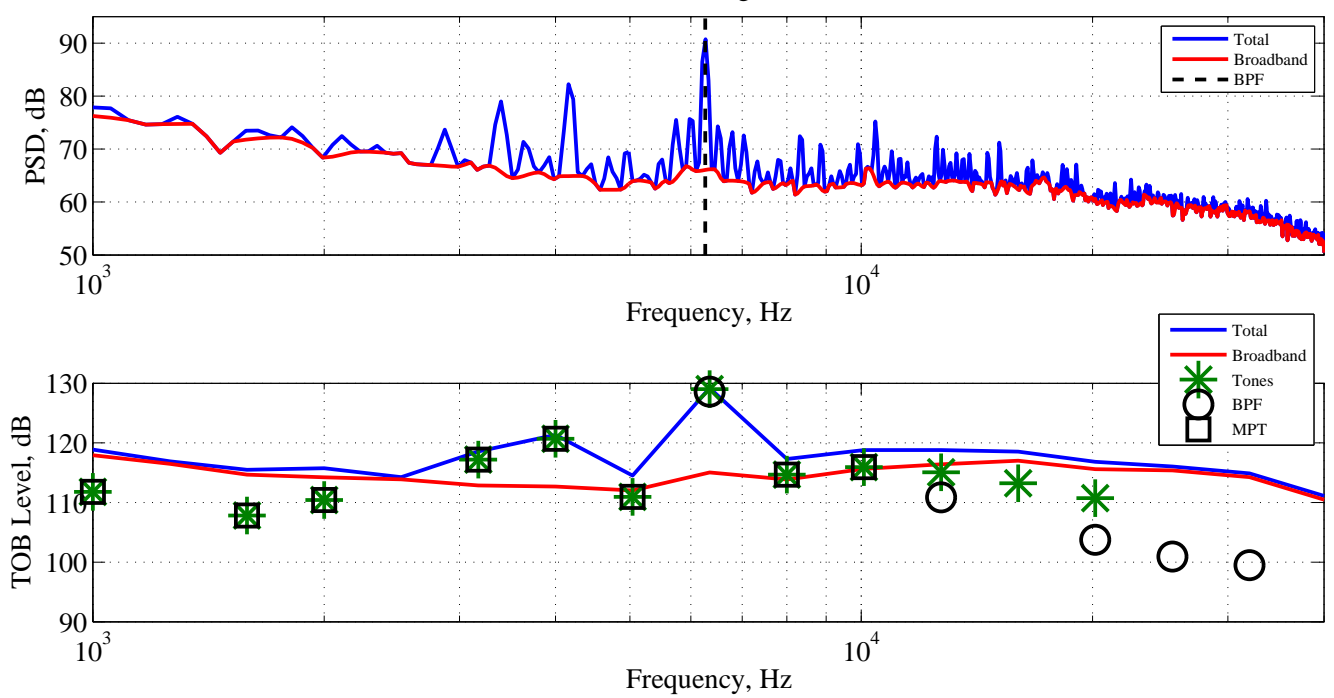

Figure 2: Example processing showing how narrowband spectra (top figure) is separated to quantify broadband and resulting one-third octave band levels (bottom figure).

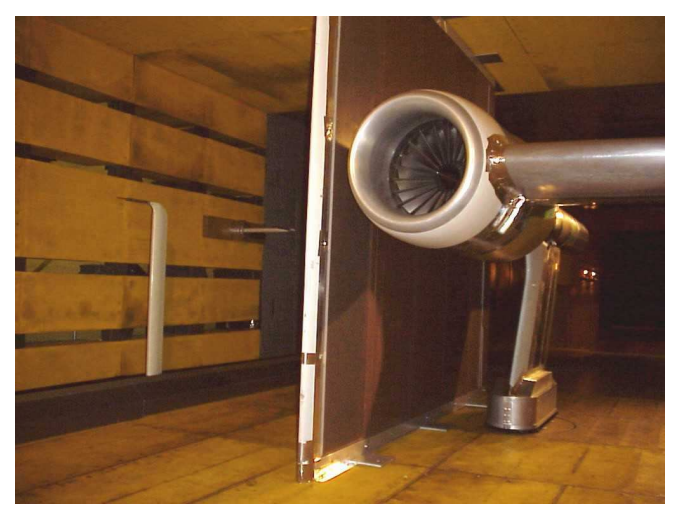

Figure 3: The 2-stage fan in the $9 \times 15$ LSWT in 2002. The acoustic barrier wall and traversing microphone are visible.

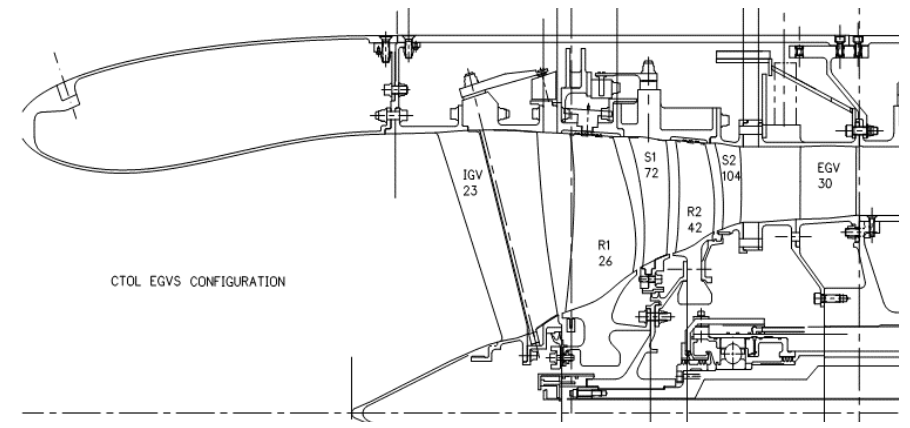

Figure 4: The 2-stage fan cross section showing IGVs, rotors and stators.

\section{Two-Stage Fan Data Review}

The two-stage fan was designed and built by Pratt \& Whitney as part of the NASA HSR program. The HSR program ended before it was tested. It was later run in a test campaign organized by GE as part of the DARPA Quiet Supersonic Platform (QSP) project. Results from this test have not been widely publicized, so a brief review of the test is appropriate. The purpose of the test was to obtain a baseline acoustic signature for HSCT fans. The fan model was tested with two sets of inlet guide vanes (IGVs), variable spacing between IGV and the first fan (R1), along with variable R1 and stator spacing. The IGVs were variable pitch and operated on a schedule with fan speed such that the IGVs unloaded the fan at low speeds. The first stator set pitch angle was also variable. A 2-D bifurcated inlet was designed and manufactured, but testing was only conducted using a subsonic inlet, as shown in Figure 3. A cross-section of the fan showing the IGVs and multiple fan rotors is given in Figure 4. The $0.48 \mathrm{~m}$ (19 inch) rig test was only operated up to $91.2 \%$ speed, or 16270 RPM. A number of hardware configurations were tested in the 9x15 LSWT, but only the variable IGV/R1 spacing and IGV/R1 acoustic treatment configurations are reported here. These are listed in Table 2. 
Table 2: Two-Stage Fan Test Configurations.

\begin{tabular}{|c|c|c|}
\hline Configuration & IGV/R1 Spacing & IGV/R1 Spacer \\
\hline 1 & Nominal & N/A \\
\hline 2 & Open & Hardwall \\
\hline 3 & Open & Treated \\
\hline
\end{tabular}

\section{V.A. Spectral Level Comparisons}

The tone levels were predicted using the HSRNOISE fan model. The first four BPF tones are compared in Figure 5. It can be seen that the first BPF tone level prediction passes through the measured points. The fall-off with emitted angle is reasonably well captured, but individual angle measurements are not well predicted, with individual angles missing by about $5 \mathrm{~dB}$ or more. The measured tone power level was 131.7 $\mathrm{dB}$, while the model prediction is $129.7 \mathrm{~dB}$. The finding for the first BPF harmonic is similar. The third and fourth harmonics are under-predicted, but the levels are low enough to such that they do not significantly contribute to the total noise level.

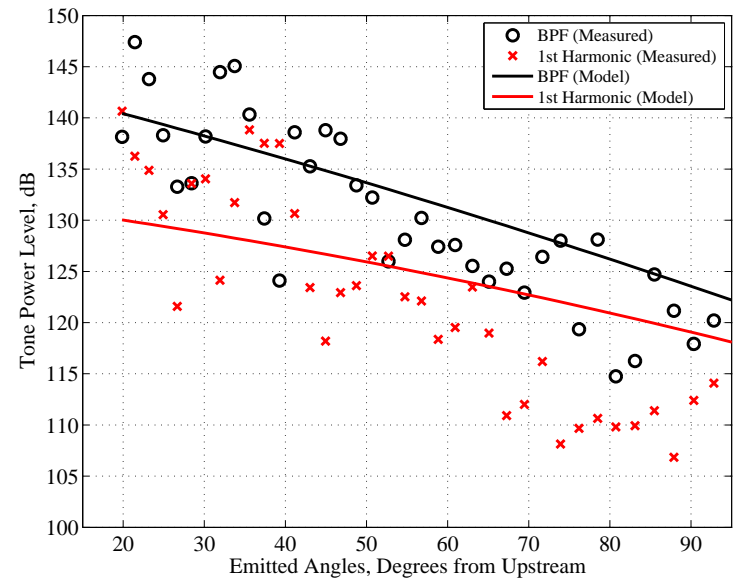

(a) BPF Tone and 1st Harmonic

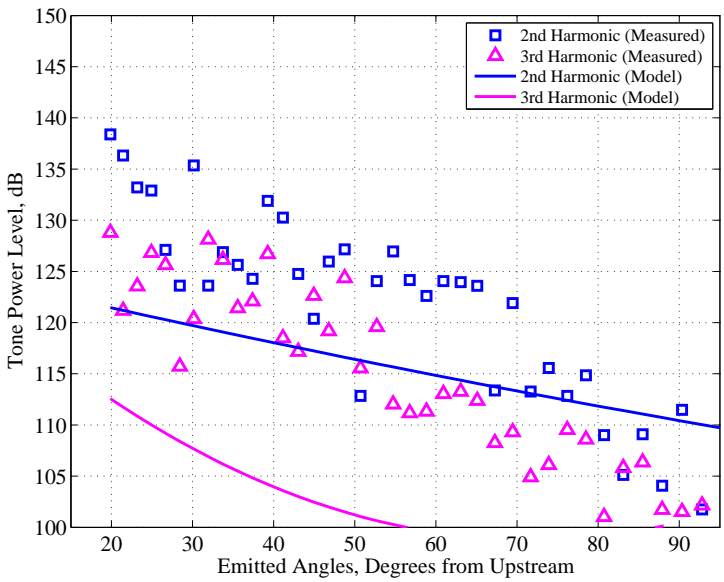

(b) BPF 2nd and 3rd Harmonics

Figure 5: Two-stage fan model, first fan BPF tones compared against fan models.

The BPF tone from the second fan stage was found to be more than $20 \mathrm{~dB}$ lower than the first fan stage, and this was the case across other directivity angles and model configurations. The HSRNOISE fan model is based on data from a 3 -stage fan, but considered only noise due to the first fan stage. ${ }^{10}$ The wind tunnel test data suggests this is a valid approach.

The broadband noise predicted by the HSRNOISE fan model is compared against measurements in Figure 6. The broadband noise spectrum is very weakly dependent on the radiation angle. This is a feature of the peak broadband noise level function for values of tip speed around $1300 \mathrm{ft} / \mathrm{s}$, as shown in Figure 3.6 .1 of the HSRNOISE manual. ${ }^{10}$ The predicted amplitude is also significantly lower than the experiment. This could be because the model is scaled down considerably from a full-sized engine. The actual scale factor is not known, as details of the XF-120 engine are not publicly available.

\section{V.B. IGV Tone Noise Reduction}

The use of IGVs is known to cause additional inlet radiating fan noise. The two-stage fan test hardware included previsions for reducing tone noise due to IGVs. The spacing between the IGV and first rotor can be increased, and additionally the spacer can be acoustically treated. Both of these changes were found to significantly reduce the sound power level of the BPF tones, as shown in Figure 7. The sound power was calculated by integrating the sound pressure level of the tone of interest over all the angles measured, and assuming azimuthal symmetry. The aft noise was shielded by the barrier wall. At the maximum fan speed tested (92.1\%), the baseline tone power was measured to be $132 \mathrm{~dB}$. Increasing the IGV/R1 spacing 


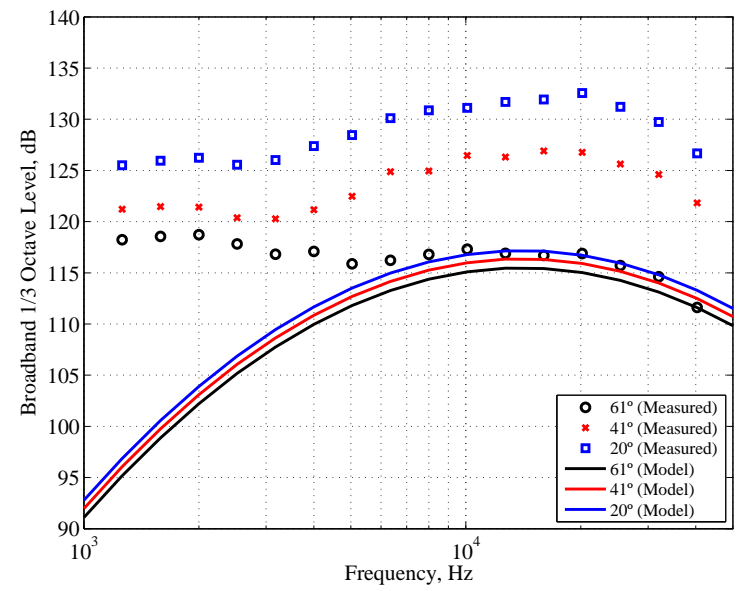

Figure 6: Broadband noise measured vs model for two-stage fan.

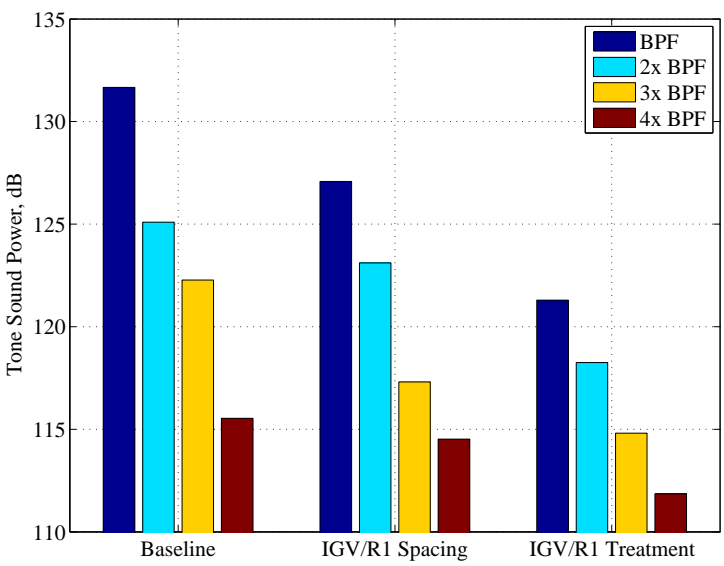

Figure 7: Tone power level reduction.

decreased the power to $127 \mathrm{~dB}$. Using an acoustically treated spacer further reduced the sound power to 121 $\mathrm{dB}$.

A simple curve-fit to the tone sound pressure level reduction is provided here for use in future fan noise predictions. The BPF tone directivity as measured is given in Figure $8 \mathrm{a}$ ), and the reduction is given in part b) of the same figure. The use of a treated IGV/R1 spacer gives a 6 to $11 \mathrm{~dB}$ reduction in the BPF tone sound pressure level, with more benefit observed towards $90^{\circ}$.

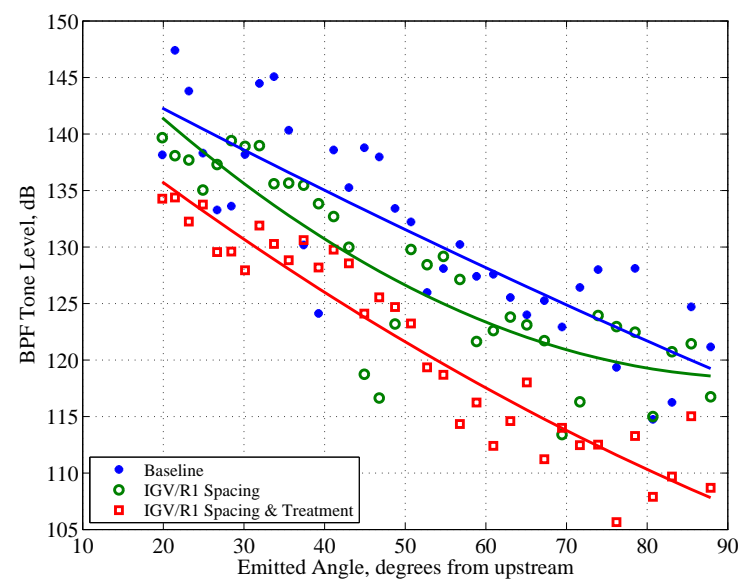

(a) Measured BPF Tone Directivity

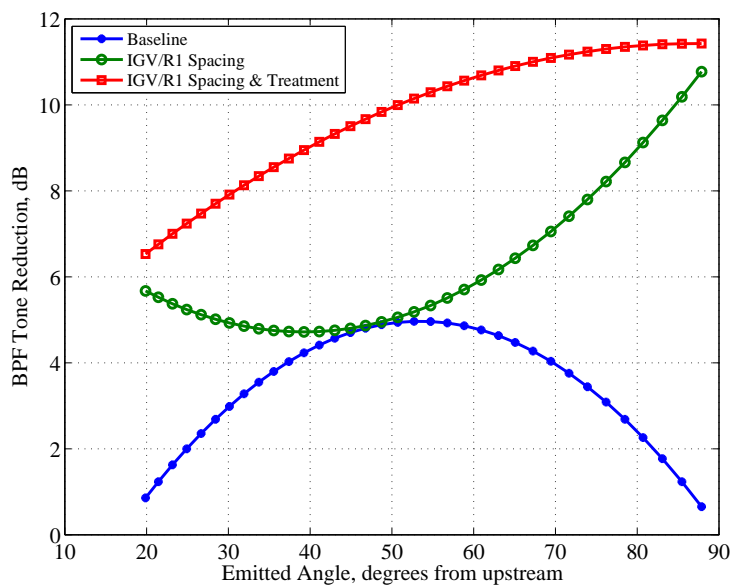

(b) 2nd Order Fit to Tone Level Reduction

Figure 8: Effect of tone noise reduction technology for two-stage fan.

\section{GE High Speed Fan Data Review}

The GE HSF test was a series of three fans and three stator sets designed and built by General Electric Aircraft Engines (GEAE) and tested as part of the NASA Advanced Subsonic Technology (AST) program in 1999. The full matrix of nine combinations was tested, and six of these combinations were also tested with the barrier wall installed to isolate inlet radiated noise. A number of reports have been published about the fan performance and acoustics results from this test. ${ }^{15-18}$ The GE HSF data set was found to be ideal for evaluating a high-tip speed single-stage fan against the existing fan models. A photograph of the GE HSF in the 9x15 LSWT is shown in Figure 9.

The fan and stator sets were designed to the same aerodynamic performance. With respect to the Heidmann fan noise model, the different combinations are all identical except for the blade/vane counts. 


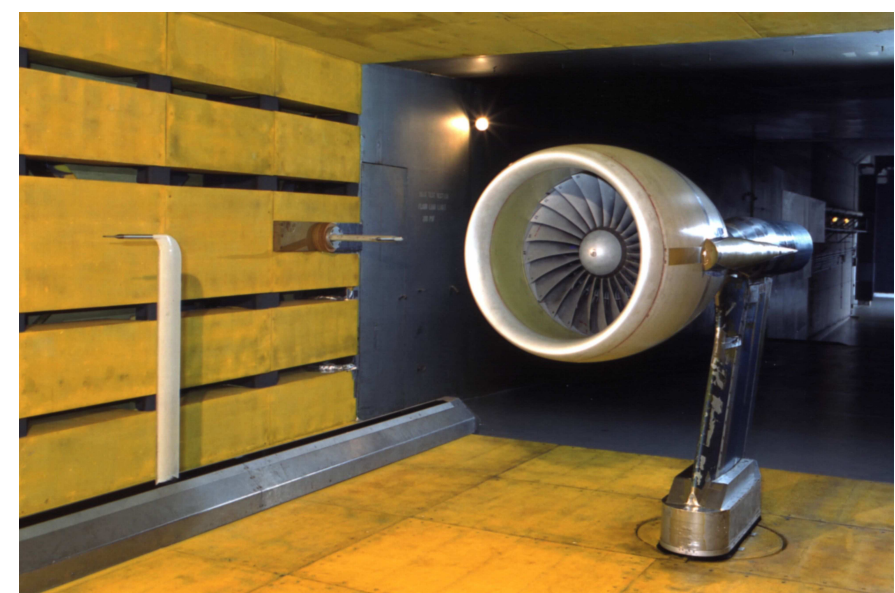

Figure 9: The GE High-Speed Fan test in the 9x15 LSWT in 1999.

Diameters, tips speeds, and efficiency were all very close between the models, both in design and during testing. The GE HSF shrouded fan model is representative of the CF6 fan.

All 4 variations of the Heidmann fan model were evaluated for the GE HSF test cases when the barrier was installed, a total of 6 configurations tested at 12 fan speeds each and with 31 directivity measurements. An "error" was computed by taking the average of the absolute value of the difference in decibels between the sound pressure level of the experiment and the model at each frequency and directivity angle. This method does not emphasize the tones or frequencies that may be important in perceived annoyance. It was used only to determine which model was the closest fit to the data. The results are shown in Figure 10. Focusing on values near $100 \%$ speed, it can be seen that the GE model is the best fit for the MPT and broadband components of the sound spectra while the Honeywell/AlliedSignal method should be used for the BPF tones. The "takeoff" inflow distortion cleanup switch was used when evaluating the GE BPF tone model.
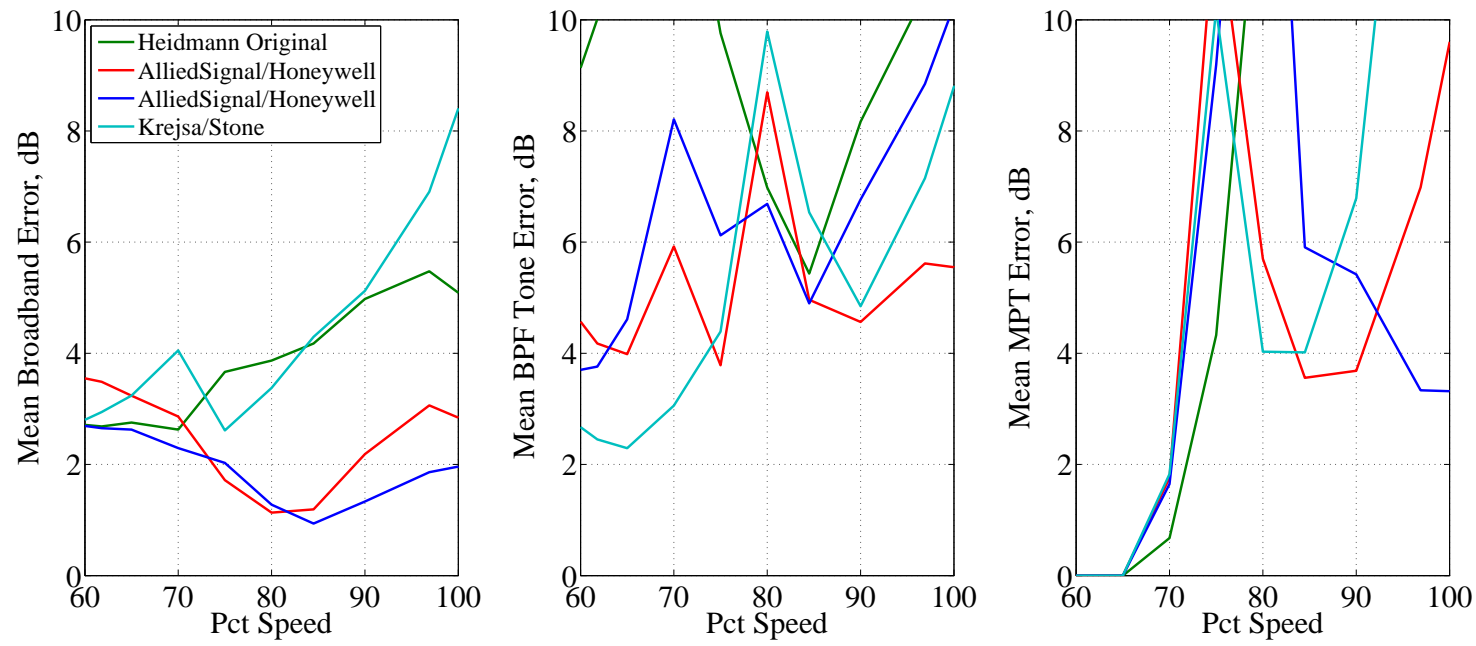

Figure 10: Sum of OASPL error for each of the three inlet components for each of the four Heidmann fan prediction methods when evaluated for the GE HSF.

Figure 11 shows six gray curves, one for each of the rotor/stator combinations at $100 \%$ fan speed. The figures on the left side designated (a), (c) and (e) show one-third octave band spectra at $52^{\circ}$ emission angle. The three right-side figures (b), (d) and (f) show the overall sound pressure level (OASPL) as a function of emission angle. Figures 11 (a) and (b) show the broadband noise, compared with the GE Aircraft Engines 
version of the Heidmann fan model. It can be seen that there is excess low frequency and aft radiated noise, but the model generally works well. This excess noise may be related to the fan bypass flow impinging on the drive rig strut in the tunnel, in which case it would be an artifact of the model scale testing and not expected to be present in an actual aircraft. Figures 11 (c) and (d) show the first four BPF tones, along with the GE Aircraft Engines and AlliedSignal/Honeywell fan models. The GE model over-predicts the measured levels at all angles while the AlliedSignal/Honeywell model passes through the measured data. It is recommended to use the AlliedSignal/Honeywell fan model for BPF tones. Figures 11 (e) and (f) show the MPT noise, along with the GE fan model. Both spectral shape and overall amplitude are well predicted.

\section{Quiet High Speed Fan Data Review}

The QHSF was a forward swept fan designed by Honeywell and tested in 2000. A baseline fan model was also tested, a scale model of the fan used on the Honeywell TFE731-60 engine. This test included two fans: a baseline design and one with forward swept blades. The forward swept fan was specifically designed for EPNL reduction for takeoff conditions. A report on the aerodynamic and acoustic performance of the fans tested is given in. ${ }^{19}$ The QHSF model is shown in Figure 12.

The QHSF data was used to confirm the conclusions about the Heidmann fan model derived from the investigation on the GE HSF. The fan performance target was a slightly higher pressure ratio and tip speed, as given in Table 1. The highest tip speed case was compared to the four fan models, and the results are shown in Figure 13. This plot is in the same format as Figure 11. Both the QHSF and the baseline fan are shown. The spectral content of the broadband noise at $52^{\circ}$ emitted angle is given in Figure 13. The Krejsa/Stone model is a good match at this angle, but as seen in Figure 13 (b), at other angles the GE method works better. For BPF tones, the Honeywell model is a good fit, and in Figure 13 (c) it can be seen that the QHSF BPF tone is more than $7 \mathrm{~dB}$ lower than the baseline fan at $52^{\circ}$ emitted angle. Considering all the BPF tones and harmonics, Figure 13 (d) shows that the AlliedSignal/Honeywell model is the best fit. This fan exhibited very low MPT levels, as shown in Figure 13 (e) and (f). The GE model for MPTs over predicts the measured levels by the smallest amount, and so is the best fit, although it might be appropriate to exclude MPTs from the prediction altogether.

\section{Simulated Flyovers}

The wind tunnel measurements and the fan noise models can each be used to create simulated flyovers. The tunnel data were modified according to the process published by Berton ${ }^{20}$ where data acquired in the 9x15 LSWT were used in a simulated flyover. The source motion exponent was taken to be 4, for both experimental and model data. A level flight of $305 \mathrm{~m}$ (1000 foot) was used, along with a flyover Mach number of 0.30. Only inlet radiated fan noise was included, so this does not represent an estimate for the total aircraft noise, or even an entire engine. Both sets of simulated flyover sound pressure levels were increased by $4.8 \mathrm{~dB}$ to account for three engines. No ground reflection is included. The flyover noise levels were sampled at the observer location at 0.5 second intervals

\section{VIII.A. Two-Stage Fan Flyover}

The two-stage fan was scaled to the engine size described in the 1044 publication, ${ }^{3}$ that is a $1.65 \mathrm{~m}(65$ inch) diameter or a linear scale factor of 3.42. The HSR fan noise model was used with the same fan tip speed as the experiment, 4755 RPM scaled from the experimental fan speed of 16270 RPM. The hardwall baseline configuration of the experiment was used, since the HSR fan noise model does not incorporate these noise-reduction features. This tunnel data was collected at 0.15 Mach. Results are shown in Figure 14. As expected given the data shown in Figure 5, the tones measured in the experiment lead to a much more complicated directivity than the model. The peak PNLT is different by $4.2 \mathrm{~dB}$. However, the EPNL metric smooths the results, and the two predictions agree to within $0.5 \mathrm{~dB}$. The small circles indicate the first and last points in the flyover PNLT that were found to be within $10 \mathrm{~dB}$ of the peak in PNLT. Both the experiment and the model show that the flyover is tone dominated, as the Perceived Noise Level (PNL) is about $5 \mathrm{~dB}$ less than the PNL Tone Corrected (PNLT). The additional low-frequency noise found in the experiment (see Figure 6) causes the PNL/PNLT curves to rise and decay more slowly than those predicted by the model, but does not cause a significant EPNL impact. 


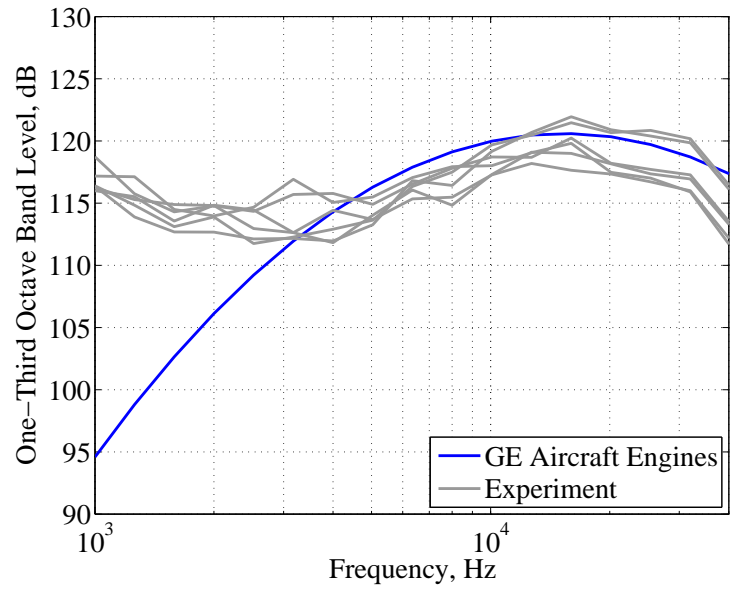

(a)

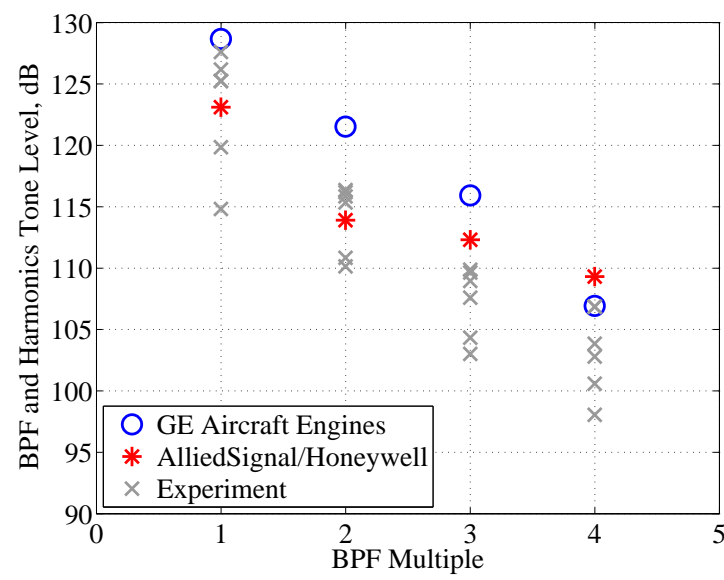

(c)

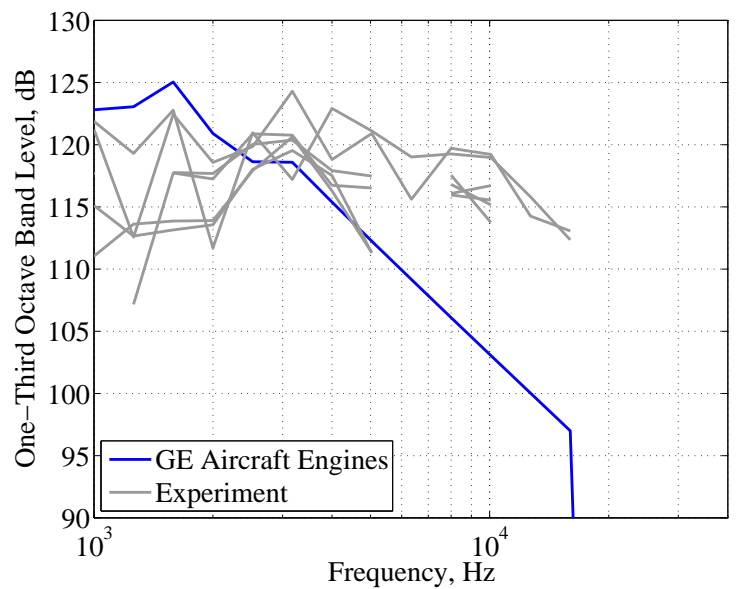

(e)

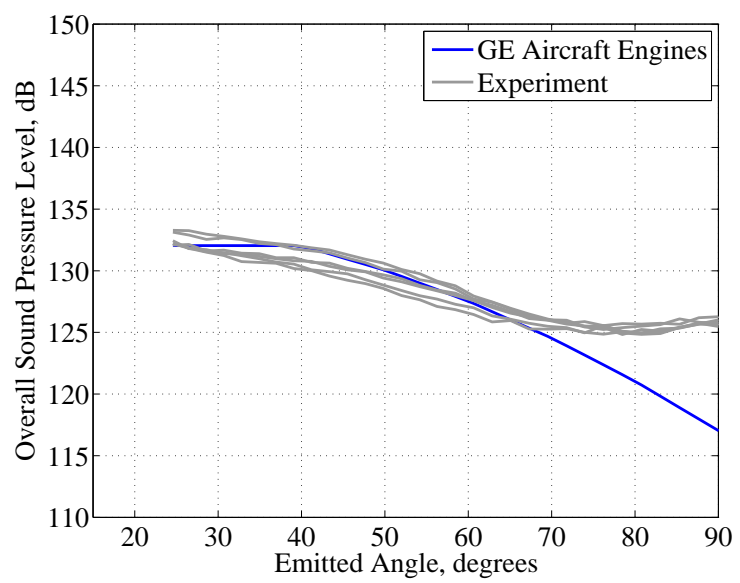

(b)

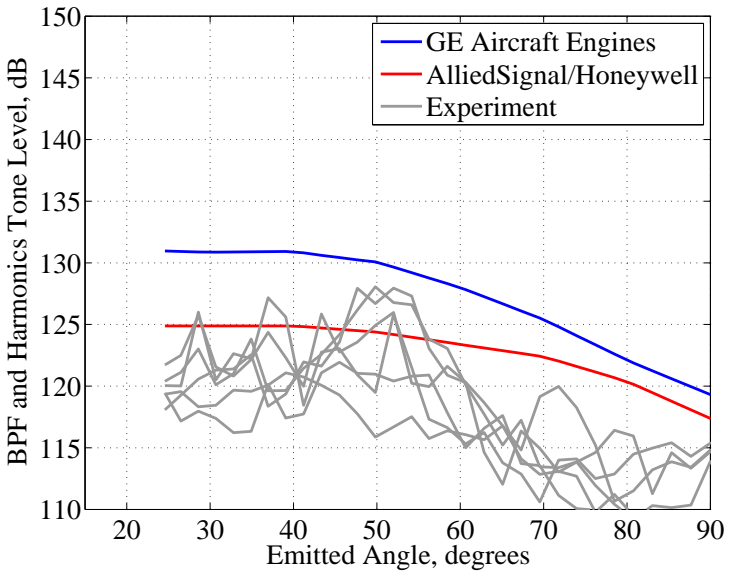

(d)

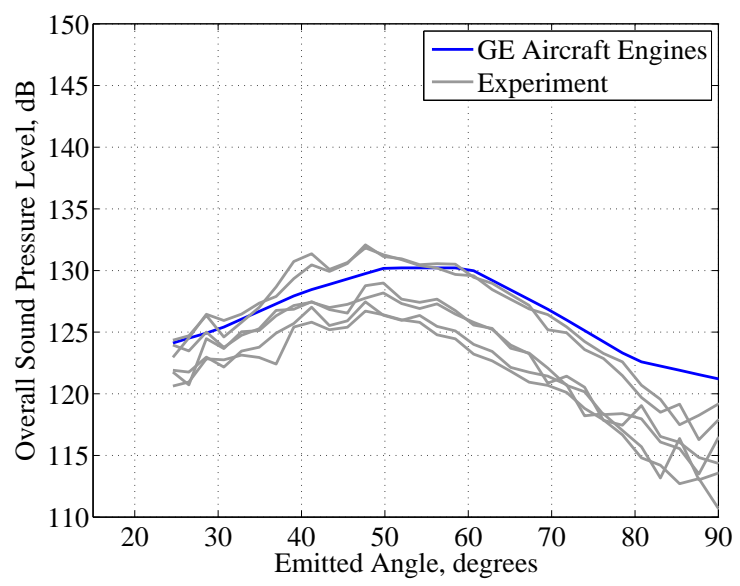

(f)

Figure 11: Model vs experiment for the 6 fan and stator combinations of the GE HSF tested in the 9x15 LSWT at $100 \%$ speed. (a) Broadband spectra at $52^{\circ}$ emitted angle. (b) Broadband overall sound pressure level directivity. (c) Blade passing tone level at $52^{\circ}$ emitted angles. (d) BPF overall sound pressure level directivity. (e) Multiple pure tone spectra at $52^{\circ}$ emitted angle. (f) MPT overall sound pressure Level directivity. 


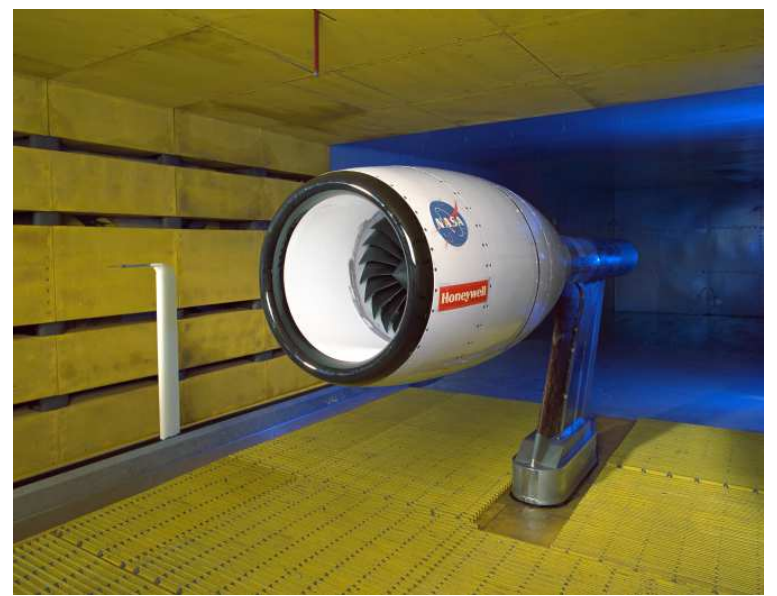

Figure 12: The Honeywell Quiet High Speed Fan test in the 9x15 LSWT in 2000.

The EPNL decibel level was calculated for all fan speeds measured during the two-stage fan test, and the results are plotted in Figure 15. This result shows satisfactory overall agreement between the fan noise experiment and the model. The impact of the IGV/R1 spacer and acoustic treatment on the EPNL is also shown, indicating up to $6 \mathrm{~dB}$ EPNL reduction for the highest speed measured. The configurations were given in Table 2.

\section{VIII.B. Quiet High Speed Fan Flyover}

Simulated flyovers were also conducted using the QHSF measured data and the Heidmann fan model, using the same methods as described in Section VIII.A. The GE method was used for broadband and the Honeywell method was used for the BPF tone and harmonics. The MPTs were excluded based on the QHSF test data, and because part of the design intent of the QHSF was to reduce MPTs. ${ }^{19}$ The single-stage fan was scaled to $2.34 \mathrm{~m} \mathrm{(92.2)} \mathrm{inch} \mathrm{diameter,} \mathrm{based} \mathrm{on} \mathrm{achieving} \mathrm{the} \mathrm{same} \mathrm{fan} \mathrm{thrust} \mathrm{as} \mathrm{the} \mathrm{two-stage} \mathrm{fan} \mathrm{but} \mathrm{with} \mathrm{the}$ lower pressure ratio. The flyover noise levels are plotted in Figure 16. The EPNL generated the fan model is high than that produced by the wind tunnel data by $5.7 \mathrm{~dB}$. The higher peak PNLT for the model is likely due to the over-prediction of the tone noise radiated at angles greater than $60^{\circ}$, as seen in Figure 13 (d). Compared to the two-stage fan results shown in Figure 15, the single-stage fan might be expected to produce between 5 and 10 EPNL dB lower noise.

\section{Conclusions}

Fan noise prediction models were compared with rig data for three high speed fans. A two-stage fan experiment provided a useful data set for evaluating the HSRNOISE fan model. Regarding the two stage fan, the following conclusions were reached.

- The first fan stage dominates the inlet radiated fan noise. The second stage fan tones were barely measurable by comparison.

- The HSR noise fan model was found to do a modestly good job at predicting the tone noise from the 2-stage fan rig. Predicted tone power level was $2 \mathrm{~dB}$ less than measured in the experiment, but directivity was well captured. Broadband noise was significantly under-predicted.

- Flyover noise was well predicted, since the main contribution was from the BPF tone. The flyover time histories exhibited differences due to the tone directivity patterns, but the EPNL metric agreed to within $1 \mathrm{~dB}$.

- The tone noise reduction due to IGV/R1 spacing and acoustic treatment was quantified. The acoustically treated spacer reduced tone sound power by $11 \mathrm{~dB}$. This corresponded to a $6 \mathrm{~dB}$ EPNL reduction in the simulated flyover noise using the experimental data. 


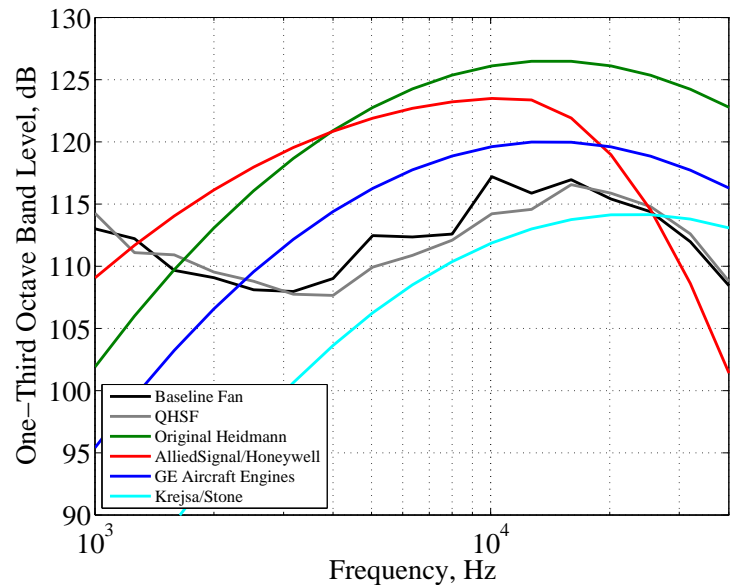

(a)

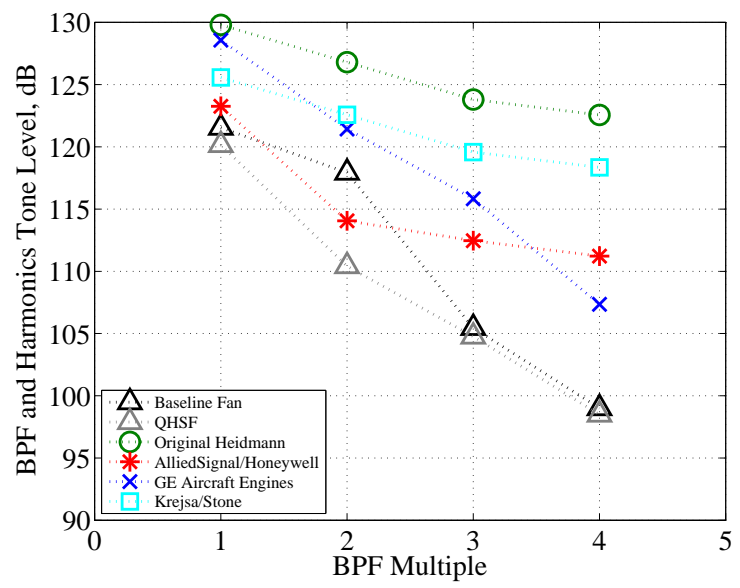

(c)

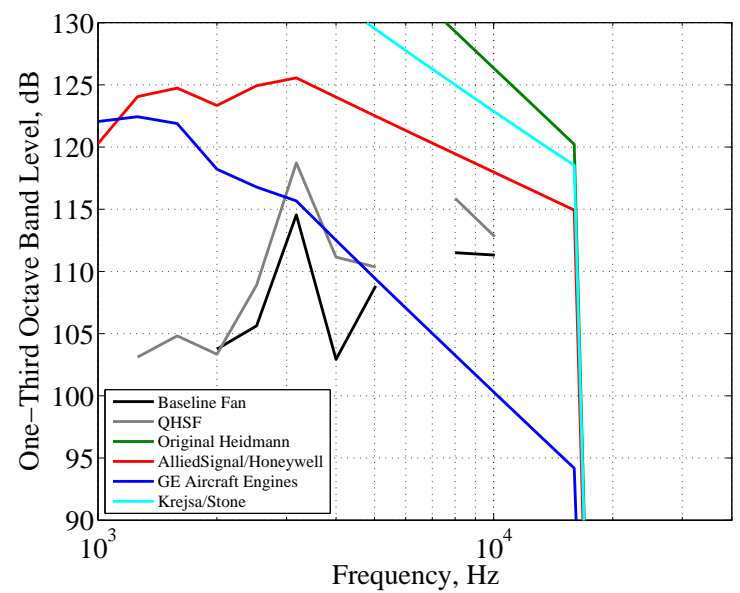

(e)

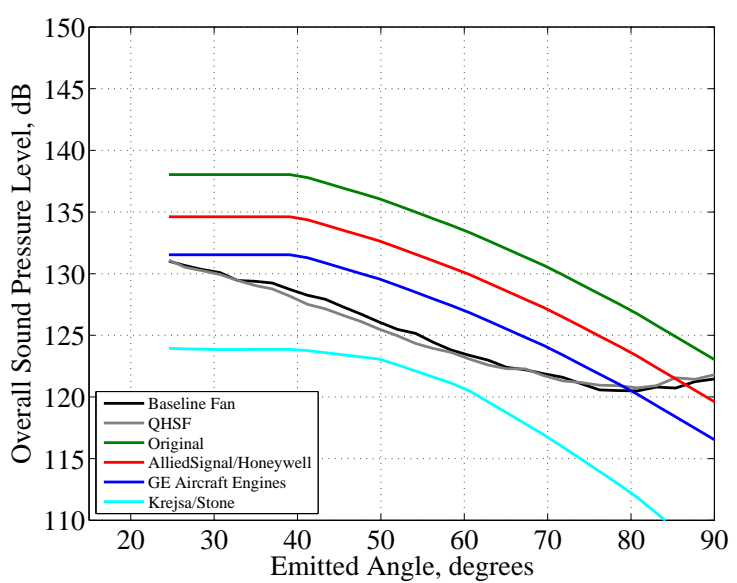

(b)

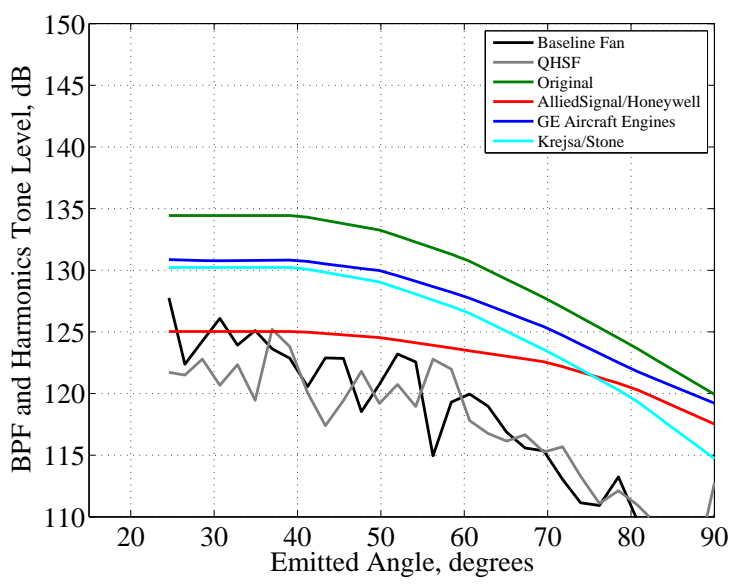

(d)

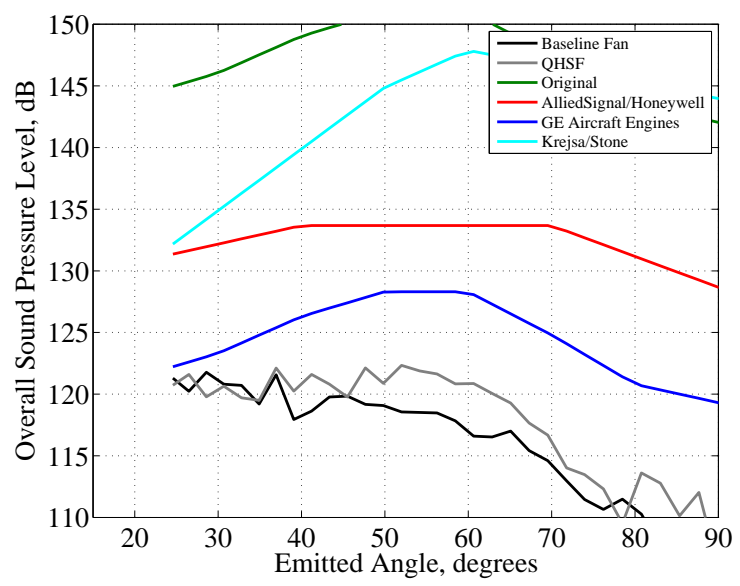

(f)

Figure 13: Model vs experiment for the Quiet High Speed Fan and Honeywell Baseline fan at 100\% speed. (a) Broadband spectra at $52^{\circ}$ emitted angle. (b) Broadband overall sound pressure level directivity. (c) Blade passing tone level at $52^{\circ}$ emitted angles. (d) BPF overall sound pressure level directivity. (e) Multiple pure tone spectra at $52^{\circ}$ emitted angle. (f) MPT overall sound pressure Level directivity. 


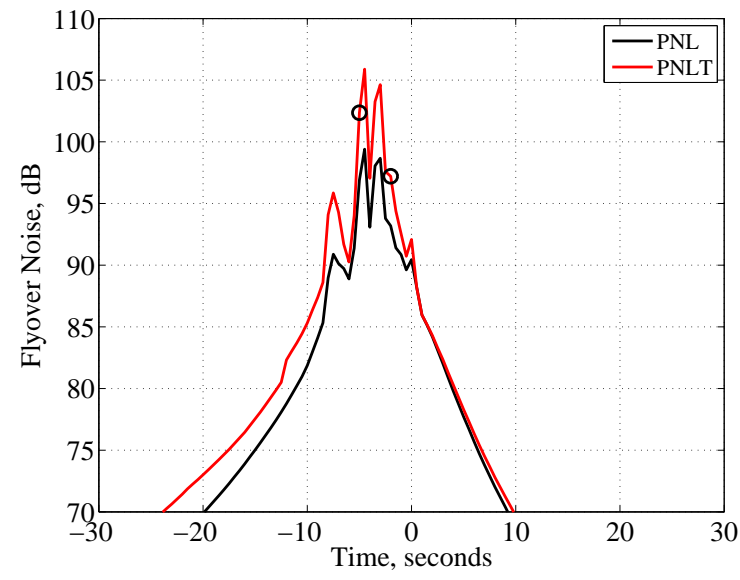

(a) Simulated flyover from data, EPNL $=97.9 \mathrm{~dB}$.

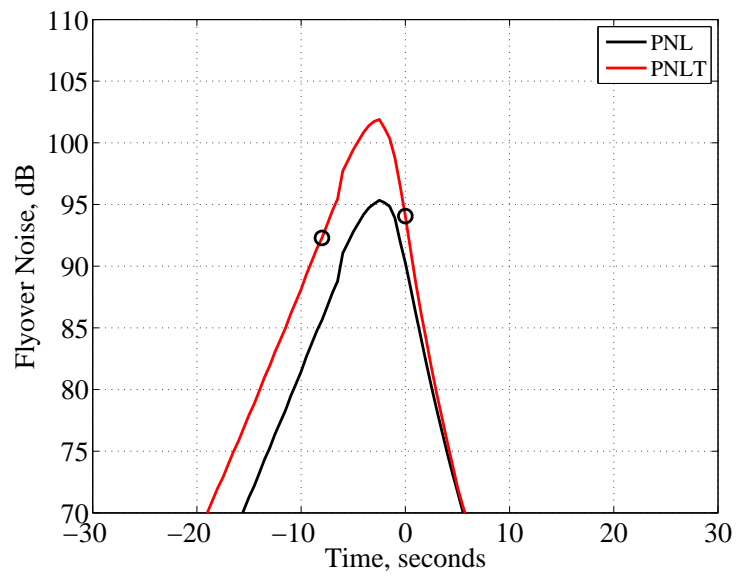

(b) Simulated flyover from model, EPNL $=98.4 \mathrm{~dB}$.

Figure 14: PNL and PNLT noise levels from simulated flyovers of 2-stage fan at $92 \%$ fan speed.

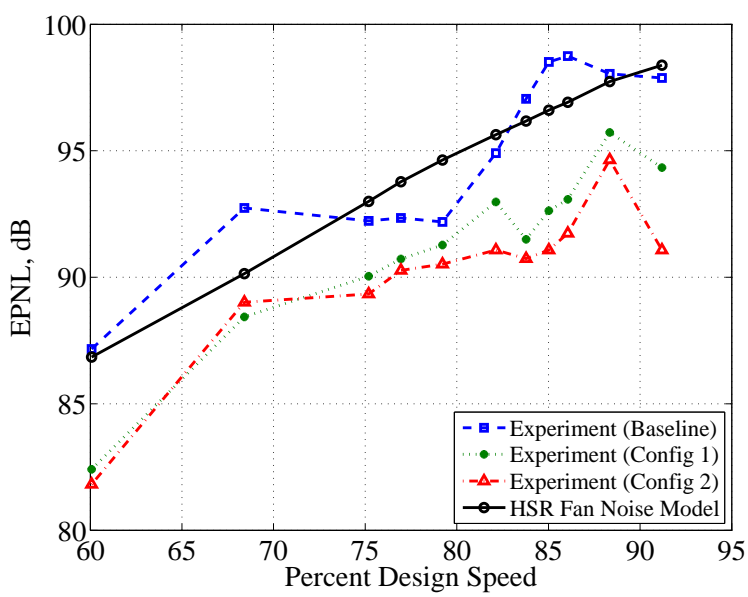

Figure 15: EPNL vs percent fan speed for the two-stage fan.

Data from two single stage fan tests was also analyzed. The GE HSF data set included six rotor/stator combinations. A few observations can be made about the prediction of fan noise from high speed single stage fans.

- The variation of the Heidmann fan model as modified by GE Aircraft Engines was the best fit for broadband noise while the AlliedSignal/Honeywell version of the Heidmann model provided the best fit for BPF tones for fan speeds near 100\%. This observation is true for both the GE HSF and the Honeywell QHSF data comparisons.

- The GE MPT prediction was a good fit for the GE HSF, but significantly over-predicted the MPTs in the QHSF. It may not be necessary to include MPTs in fan noise predictions, depending on installation.

- All three inlet-radiated components of fan noise were over-predicted compared to the Honeywell QHSF test data. This led to an over-prediction of EPNL when simulated flyovers were considered.

\section{Acknowledgments}

The NASA Commercial Supersonic Technology project of the Advanced Air Vehicles Program funded this report. 


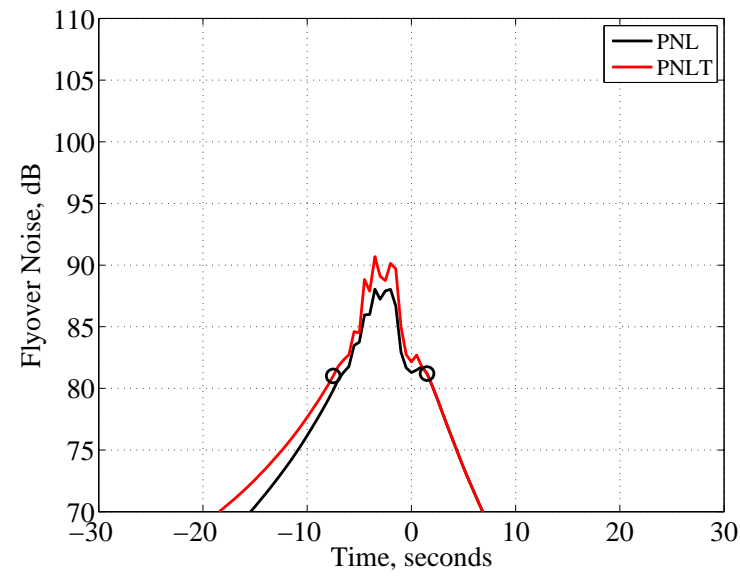

(a) Simulated flyover from data, EPNL $=86.3 \mathrm{~dB}$.

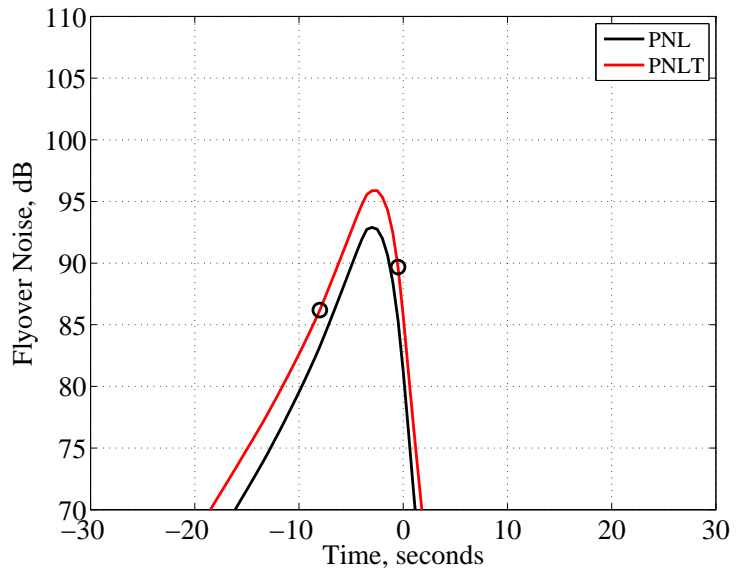

(b) Simulated flyover from model, EPNL $=92.0 \mathrm{~dB}$.

Figure 16: PNL and PNLT noise levels from simulated flyovers of QHSF.

\section{References}

${ }^{1}$ Berton, J. J., Haller, W. J., Senick, P. F., Jones, S. M., and Seidel, J. A., "A Comparative Propulsion System Analysis for the High-Speed Civil Transport," NASA TM-2005-213414, February 2005.

${ }^{2}$ Huff, D. L., Henderson, B. S., Berton, J. J., and Seidel, J. A., "Perceived Noise Analysis " Offset Jets Applied to Commercial Supersonic Aircraft AIAA-2016-1635," NASA GRC-E-DAA-TN28452, January 2016.

${ }^{3}$ Morgenstern, J., Buonanno, M., Yao, J., Murugappan, M., Paliath, U., Cheung, L., Malcevic, I., Ramakrishnan, K., Pastouchenko, N., Wood, T., Martens, S., Viars, P., Tersmette, T., Lee, J., Simmons, R., Plybon, D., Alonso, J., Palacios, F., Lukaczyk, T., and Carrier, G., "Advanced Concept Studies for Supersonic Commercial Transports Entering Service in the 2018-2020 Period Phase 2," NASA CR-2015-218719, July 2015.

${ }^{4}$ Woodward, R. P., Glaser, F. W., and Lucas, J. G., "Low flight speed acoustic results for a supersonic inlet with auxiliary inlet doors," NASA TM-83411 / AIAA 83-1415, June 1983.

${ }^{5}$ Lopes, L. V. and Burley, C. L., "Design of the Next Generation Aircraft Noise Prediction Program: ANOPP2 AIAA2011-2854," NASA NF1676L-11643, June 2011.

${ }^{6}$ Heidmann, M. F., "Interim prediction method for fan and compressor source noise," NASA TM-X-71763, June 1979.

${ }^{7}$ Hough, J. W. and Weir, D. S., "Aircraft Noise Prediction Program (ANOPP) Fan Noise Prediction for Small Engines," NASA-CR-198300, April 1996.

${ }^{8}$ Kontos, K. B., Janardan, B. A., and Gliebe, P. R., "Improved NASA-ANOPP Noise Prediction Computer Code for Advanced Subsonic Propulsion Systems," NASA-CR-195480, August 1996. 2014.

${ }^{9}$ Krejsa, E. A. and Stone, J. R., "Enhanced Fan Noise Modeling for Turbofan Engines," NASA-CR-2014-218421, December

${ }^{10}$ John W. Rawls, J. and Yeager, J. C., "High Speed Research Noise Prediction Code (HSRNOISE) Users and Theoretical Manual," NASA-CR-2004-213014, November 2004.

${ }^{11}$ Dahl, M. D., "Assessment of NASA's Aircraft Noise Prediction Capability," NASA-TP-2012-215653, July 2012.

${ }^{12}$ Woodward, R. P., Gazzaniga, J. A., and Hughes, C. E., "Far-Field Acoustic Characteristics of Multiple Blade-Vane Configurations for a High Tip Speed Fan," NASA TM-2004-213093, May 2004.

${ }^{13}$ Weir, D. S., "Design and Test of Fan/Nacelle Models Quiet High-Speed Fan," NASA CR-2003-212370, July 2003.

${ }^{14}$ Stephens, D. B. and Vold, H., "Order tracking signal processing for open rotor acoustics," Journal of Sound and Vibration, Vol. 333, 2014, pp. 3818-3830.

${ }^{15}$ Gazzaniga, J. A., "Performance of Advanced Fan Exit Guide Vane Concepts for High Speed Fans AIAA 2002-0377," 40th Aerospace Sciences Meeting \& Exhibit, Reno, Nevada, USA, January 14-17, 2002.

${ }^{16}$ Gazzaniga, J. A., "Performance of Advanced Fan Exit Guide Vanes with a Forward Swept Fan AIAA 2003-1067," 41st Aerospace Sciences Meeting \& Exhibit, Reno, Nevada, USA, January 6-9, 2003.

${ }^{17}$ Gazzaniga, J. A., "Performance of Advanced Fan Exit Guide Vanes with a Product Derived Fan AIAA 2004-0685," 42nd Aerospace Sciences Meeting \& Exhibit, Reno, Nevada, USA, January 5-8, 2004.

${ }^{18}$ Woodward, R. P., Gazzaniga, J. A., Bartos, L. J., and Hughes, C. E., "Acoustic Benefits of Stator Sweep and Lean for a High Tip Speed Fan AIAA-2002-1034," 40th Aerospace Sciences Meeting \& Exhibit, Reno, Nevada, USA, January 14-17, 2002.

${ }^{19}$ Dittmar, J. H., Elliott, D. M., and Fite, E. B., "The Noise of a Forward Swept Fan," NASA TM-2003-212208, November 2003.

${ }^{20}$ Berton, J. J., "Empennage Noise Shielding Benefits for an Open Rotor Transport. NASA/TM-2012-217218 (AIAA20112764)," 17th AIAA/CEAS Aeroacoustics Conference (32nd AIAA Aeroacoustics Conference), Portland, Oregon, USA, June 5-8, 2011. 